\title{
Placebo response in neuropathic pain after spinal cord injury: a meta-analysis of individual participant data
}

This article was published in the following Dove Press journal: Journal of Pain Research

\author{
Catherine R Jutzeler, ${ }^{1-3}$ \\ Freda MWarner, ${ }^{1,2}$ \\ Jacquelyn J Cragg, ${ }^{1,3}$ Jenny \\ Haefeli, ${ }^{4}$ J Scott Richards, ${ }^{5}$ \\ Sven R Andresen, ${ }^{6}$ Nanna \\ B Finnerup, ${ }^{7,8}$ Catherine \\ Mercier, ${ }^{9}$ John LK Kramer ${ }^{1,2}$ \\ 'Faculty of Medicine, ICORD, \\ University of British Columbia, \\ Vancouver, BC, Canada; ${ }^{2}$ Faculty of \\ Education, School of Kinesiology, \\ University of BC, Vancouver, BC, \\ Canada; ${ }^{3}$ Faculty of Medicine, Spinal \\ Cord Injury Center, University \\ Hospital Balgrist, University of Zurich, \\ Zurich, Switzerland; ${ }^{4}$ Weill Institute \\ for Neurosciences, Department \\ of Neurological Surgery, Brain and \\ Spinal Injury Center, University of \\ California, San Francisco, CA, USA; \\ ${ }^{5}$ Department of Physical Medicine \\ and Rehabilitation, University of \\ Alabama at Birmingham, Birmingham, \\ AL, USA; ${ }^{6}$ Spinal Cord Injury Centre \\ of Western Denmark, Department \\ of Neurology, Regional Hospital of \\ Viborg, Viborg, Denmark; ${ }^{7}$ Danish \\ Pain Research Centre, Department of \\ Clinical Medicine, Aarhus University, \\ Aarhus, Denmark; ${ }^{8}$ Department \\ of Neurology, Aarhus University \\ Hospital, Aarhus, Denmark; ${ }^{\circ}$ Center \\ for Interdisciplinary Research in \\ Rehabilitation and Social Integration, \\ Québec, QC, Canada
}

Correspondence: Catherine R Jutzeler ICORD, University of BC, $818 \mathrm{~W}$ I0th Avenue, Vancouver, BC V5Z IM9, Canada

Tel +l 6046758876

Email catherine.jutzeler@ubc.ca
Background: Understanding factors associated with high placebo responses in clinical trials increases the likelihood of detecting a meaningful treatment effect. The aim of the present study was to identify subject-level factors that contribute to placebo variability in patients with neuropathic pain due to spinal cord injury (SCI).

Methods: Multiple regression analysis of patient data from randomized, double-blind, placebocontrolled trials (duration $>4$ weeks) involving individuals with SCI was performed. Patient demographics, as well as injury and pain characteristics were examined for their association with changes in pain rating from baseline to the end of the trial (i.e., placebo response). The overall effect of individual predictors was quantified with meta-analysis statistics.

Results: A total of 276 patients with SCI from six studies were included in the analysis. Based on the meta-analysis of subject-level predictors, larger placebo responses were associated with male subjects $(\beta=0.635$; standard error $[\mathrm{SE}]=0.262 ; p=0.016)$ and higher baseline pain $(\beta=-0.146$; $\mathrm{SE}=0.073 ; p=0.044)$. There were no significant effects for injury characteristics (i.e., severity, level, and time since injury) or pain characteristics (i.e., location and evoked). No significant publication bias was detected.

Conclusion: The current meta-analysis of individual patient data demonstrated the importance of sex and baseline pain intensity on changes in pain ratings in the placebo arm of SCI central neuropathic pain randomized controlled clinical trials. Overall, our findings indicate that placebo responses occur independent of injury characteristics.

Keywords: placebo response, clinical trial, spinal cord injury, neuropathic pain

\section{Introduction}

The placebo effect represents a major challenge for the design of clinical trials aimed at relieving chronic pain. The difficulty stems from large changes in pain without an active intervention, which potentially masks meaningful treatment effects. The "placebo problem" is compounded by limited prediction of treatment effects based on preclinical pain models. ${ }^{1-3}$ Understanding factors underlying placebo responses has, as a consequence, emerged as an approach to improve the design and interpretation of chronic pain clinical trial outcomes. ${ }^{4-7}$

Central neuropathic pain arises because of damage in the central nervous system (CNS), and is common in individuals with multiple sclerosis, stroke, and spinal cord injury (SCI) ${ }^{8-10}$ Interestingly, clinical trials in SCI neuropathic pain report smaller placebo responses relative to other neuropathic pain conditions (e.g., diabetic and HIV neuropathy). ${ }^{11}$ This difference raises the possibility that unique factors associated 
with central neuropathic pain (e.g., damage in the CNS) contribute to lower placebo responses. A recent metaanalysis identified that longer pain duration and greater between-subject baseline pain variability were associated with a decreased placebo response in patients with central neuropathic pain. ${ }^{12}$

Meta-analyses of published studies are often used to pool effect sizes. ${ }^{13,14}$ As an extension of meta-analysis, meta-regression is commonly performed to examine the relationship between effect size and study (e.g., sample size and allocation concealment) and patient-level variables (e.g., age and sex). Conventional meta-regression of pooled study data suffers from major limitations. The most substantial concern is that a correlation observed at the study level may be inversely correlated at the patient level (i.e., ecological fallacy). In addition, study-level meta-regression has limited sensitivity to detect important patient-level factors related to the outcome. To accurately derive these relationships, analysis of individual patient data (IPD) is needed. ${ }^{15-19}$ Meta-analyses of IPD are considered the gold standard for systematic reviews. ${ }^{16,20}$

To address factors associated with placebo responses in neuropathic pain, we performed a meta-analysis of patientlevel data pertaining to six placebo-controlled randomized trials (RCTs) conducted in the field of SCI. Our primary aim was to examine the effect of subject-level predictors on placebo responses. Specifically, we tested the hypothesis that patient demographics, injury, and pain characteristics contribute to the variability of placebo responses in individuals with neuropathic pain after SCI.

\section{Materials and methods}

This study was approved by the University of British Columbia's Clinical Research Ethics Board (H15-00475).

\section{Study selection: search, inclusion, and exclusion criteria}

A systematic literature search of English-language articles was performed using PubMed between September 2015 and January 2016. Search terms included "placebo", "spinal cord injury", and "pain". Hand searching was also performed, reviewing reference lists of relevant trials and comprehensive review articles. Additional search terms and combinations were considered to further identify relevant studies (e.g., "neuropathic", "central pain"). We included randomized, placebo-controlled, parallel- or crossover-designed studies for which IPD were available. Only datasets from pharmacologic studies using inert placebos and treatment durations longer than 4 weeks were included in this analysis. Case studies and open-label clinical trials (i.e., those with no placebo condition) were excluded. Based on this search, corresponding authors were contacted by email to obtain the patient-level data. Contact was also made by email for industry-sponsored studies.

\section{Predictor variables}

The following patient-level information was obtained for all subjects undergoing placebo treatment: age, sex, injury characteristics (i.e., level and severity of injury, time since injury), and pain characteristics (i.e, baseline and post-placebo pain intensity, quality of pain (i.e, evoked). The level and severity of injury were classified using the International Standards for the Neurological Classification of SCI. ${ }^{21}$ Level of injury was dichotomized as thoracic or cervical. Completeness of injury was determined according to the American Spinal Injury Association Impairment Scale (AIS) grades. Injury completeness was dichotomized as "complete" (i.e., AIS-A subjects, with no sensory or motor function caudal to the level of injury) or incomplete injuries (i.e., AIS-B to D subjects, with motor and/or sensory sparing). ${ }^{21}$

\section{Statistical analysis}

R Statistical Software version 2.15.3 was used for all analyses. Placebo response (dependent variable) was defined as the overall change in rating of the neuropathic pain intensity (i.e., based on 0-10 numeric rating scale) from baseline to the end of the study or the last measurement. As there is a known trial-design effect on placebo response ${ }^{12}$ and to enable direct comparison with the parallel-designed studies, only patients who received placebo in the first arm were included for the analysis. A priori studies from the same investigators using similar experimental design (e.g., crossover study) were pooled to increase sample size. ${ }^{22,23}$

In step 1, multivariable regression statistics were used to calculate effect sizes (beta coefficient) and a measure of variance (standard error [SE]). Subject characteristics (age and sex), injury characteristics (plegia, completeness, and duration since injury), and pain characteristics (baseline pain intensity rating) were modeled separately. In an exploratory analysis, the effects of evoked pain (i.e., allodynia) and location of pain (i.e., at-level, below-level, or both) on the placebo response were independently examined. ${ }^{22-25}$

Step 2 of our analysis examined the overall effect size of subject, injury, and pain characteristics across studies (i.e., a pooled effect size). The $\mathrm{R}$ package metafor was used to 
perform a meta-analysis on the regression coefficients derived from bivariable and multivariable regression models. ${ }^{26}$ Forest plots were produced to visualize the results from the randomeffect models ( $\mathrm{R}$ function: forest). Funnel plots were used to assess publication bias ( $\mathrm{R}$ function: funnel). To assess publication bias by examining asymmetry in the funnel plots, the Egger test was used ( $\mathrm{R}$ function: regtest). ${ }^{27}$

\section{Results}

\section{Study selection and characteristics}

The results of the study selection are presented in Figure 1. A total of six placebo-controlled studies met the inclusion criteria and were thus included in the analysis. ${ }^{22-24,28-30}$ The data of 276 chronic SCI patients were acquired from the authors of the original studies ${ }^{22-24,30}$ or industry sponsors. ${ }^{28,29}$ Six patients from one study ${ }^{24}$ had to be excluded as not all of the information required for the present study was available in the dataset. Table 1 provides a detailed overview of all the studies included. Ten studies were excluded from the analysis because of the use of an active placebo $(n=2),{ }^{25,31}$

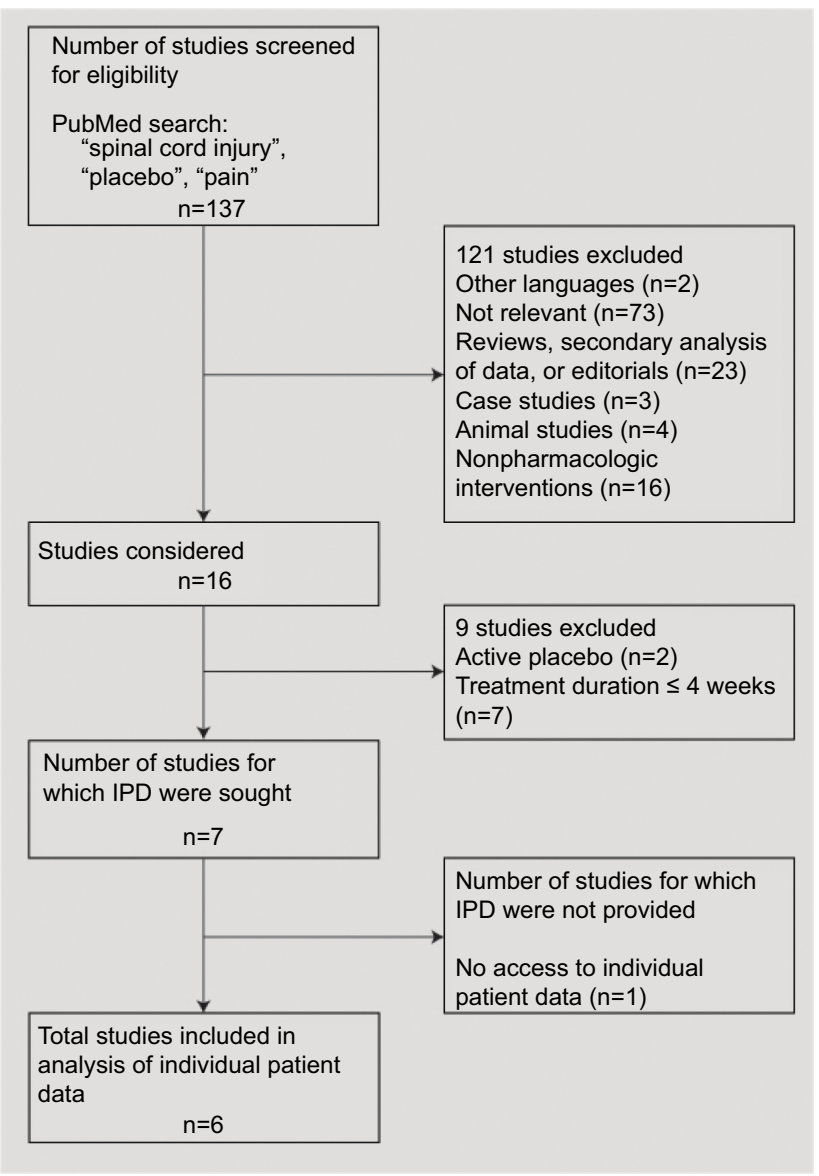

Figure I Flow diagram for the selection of randomized placebo-controlled trials. Abbreviation: IPD, individual patient data. a treatment duration $<4$ weeks $(n=7),{ }^{25,31-39}$ or no access to the IPD $(n=1) .{ }^{39}$

\section{Placebo response}

Figure $2 \mathrm{~A}$ illustrates the placebo responses for all studies reviewed $(\beta=-0.622 ; \mathrm{SE}=0.39 ; p=0.115)$. Overall, there was no significant placebo response. No significant publication bias was detected by Egger's regression test for funnel plot asymmetry ( $p=0.674$; Figure $2 \mathrm{~B})$.

\section{Multivariable regression analyses}

All results from the multivariable regression analyses are summarized in Table 2.

\section{Meta-regression: patient, injury, and pain characteristics}

Based on meta-regression statistics of individual patient-level data, sex $(\beta=0.635 ; \mathrm{SE}=0.262 ; p=0.016$; Figure $3 \mathrm{~A})$ and baseline pain intensity rating $(\beta=-0.146 ; \mathrm{SE}=0.073 ; p=0.044$; Figure 4) were associated with placebo responses. Males and higher baseline pain intensity ratings were associated with larger placebo responses. No significant publication bias was detected by Egger's regression test for funnel plot asymmetry (sex: $p=0.669$, baseline pain: $p=0.361$, placebo response: $p=0.673$ ). Age (Figure 3B), injury severity (Figure 5A), level (Figure 5B), and duration (Figure 5C) did not significantly predict placebo responses.

\section{Planned exploratory analysis}

In two available trials, evoked pain $(\beta=0.345 ; \mathrm{SE}=1.086$; $p=0.751$; Figure 6A) was not associated with placebo responses. Placebo responses were higher in individuals with below-level compared with below- and at-level neuropathic pain (i.e., both) (Figure 6B). However, this effect was not observed after adjusting for baseline pain $(\beta=0.065$; $\mathrm{SE}=0.481 ; p=0.893$; Figure 6C).

\section{Discussion}

Our study examined factors contributing to variable placebo responses in individuals with SCI neuropathic pain. For that purpose, IPD $(n=276)$ derived from six randomized clinical trials were examined. Based on a patient-level meta-approach, sex and baseline pain intensity ratings were the only variables significantly associated with placebo responses. There was a trend toward larger placebo responses in individuals with incomplete injuries (versus complete); however, this effect was not consistent across examined trials. Other neuropathic pain, injury, or subject characteristics were not related to 
Table I Details of reviewed studies

\begin{tabular}{|c|c|c|c|c|c|c|}
\hline Study details & Study I & Study 2 & Study 3 & Study 4 & Study 5 & Study 6 \\
\hline \multirow[t]{2}{*}{ Publication, author, year } & Finnerup et al, ${ }^{22}$ & Finnerup et $\mathrm{al}^{23}$ & Siddall et al, ${ }^{29}$ & Cardenas et al, ${ }^{28}$ & Richards et al, ${ }^{24}$ & Andresen et $\mathrm{al},{ }^{30}$ \\
\hline & $2009^{a}$ & $2002^{\mathrm{a}}$ & 2006 & 2013 & 2015 & 2016 \\
\hline Study design & Crossover & Crossover & Parallel & Parallel & Parallel & Parallel \\
\hline Intervention & Levetiracetam & Lamotrigine & Pregabalin & Pregabalin & Venlafaxine XR & Palmitoylethanolamide \\
\hline \multicolumn{7}{|l|}{ Duration of placebo, days } \\
\hline Mean (SD) & $29.4(11.6)$ & $61.1(2.5)$ & $61.9(30.5)$ & $17 \mid .6(9.6)$ & $81.8(9.4)$ & $82.3(22.3)$ \\
\hline \multicolumn{7}{|l|}{ Subject characteristics } \\
\hline Number & 18 & 12 & 67 & 106 & 39 & 34 \\
\hline \multicolumn{7}{|l|}{ Sex, n (\%) } \\
\hline Male & $15(83.3)$ & $10(83.3)$ & $54(80.6)$ & 91 (85.8) & $33(84.6)$ & $29(85.3)$ \\
\hline Female & $3(16.7)$ & $2(16.7)$ & $13(19.4)$ & $15(14.2)$ & $6(15.4)$ & $5(14.7)$ \\
\hline \multicolumn{7}{|l|}{ Age, years } \\
\hline Mean (SD) & $56.6(10.9)$ & $41.5(10.7)$ & $49.8(14.2)$ & $45.3(14.0)$ & 42.7 (II.I) & $54.4(\mid I .2)$ \\
\hline \multicolumn{7}{|l|}{ Injury characteristics } \\
\hline \multicolumn{7}{|l|}{ ASIA Impairment Scale ${ }^{\mathrm{b}}, \mathrm{n}(\%)$} \\
\hline A: Complete & $6(33.3)$ & $5(41.7)$ & $34(50.7)$ & $57(53.8)$ & $23(59.0)$ & $10(29.4)$ \\
\hline B: Incomplete & I (5.6) & I (8.3) & $7(10.4)$ & $10(9.4)$ & $6(15.4)$ & $3(8.8)$ \\
\hline C: Incomplete & I (5.6) & $2(16.6)$ & $7(10.4)$ & $7(6.6)$ & $5(12.8)$ & $9(26.5)$ \\
\hline D: Incomplete & $10(55.6)$ & $4(33.3)$ & $19(28.4)$ & $32(30.2)$ & $5(12.8)$ & $12(35.3)$ \\
\hline \multicolumn{7}{|l|}{ Cause of $\mathrm{SCl}, \mathrm{n}(\%)$} \\
\hline Violence (e.g., gunshot) & - & $0(0)$ & $0(0)$ & $8(7.5)$ & 14 (35.9) & $0(0)$ \\
\hline Accident (e.g., fall, vehicular) & - & $8(66.7)$ & $59(88.1)$ & $81(76.5)$ & $21(53.8)$ & $22(64.7)$ \\
\hline Other & - & $4(33.3)$ & $8(11.9)$ & $17(16)$ & $4(10.3)$ & $12(35.3)$ \\
\hline \multicolumn{7}{|l|}{ Time since injury, years } \\
\hline Mean (SD) & $4.6(4.1)$ & $13.0(9.5)$ & $10.4(9.8)$ & $10.6(10.3)$ & $16.7(13.0)$ & $11.7(I 1.1)$ \\
\hline \multicolumn{7}{|l|}{ Plegia, n (\%) } \\
\hline Paraplegia & $10(55.6)$ & $7(58.3)$ & $38(56.7)$ & $56(52.8)$ & $15(38.5)$ & $20(58.8)$ \\
\hline Tetraplegia & $18(44.4)$ & $5(4 I .7)$ & $29(43.3)$ & $50(47.2)$ & $24(61.5)$ & $14(4 \mid .2)$ \\
\hline \multicolumn{7}{|l|}{ Pain characteristics } \\
\hline \multicolumn{7}{|l|}{ Baseline pain score } \\
\hline Mean (SD) ${ }^{c}$ & $6.8(1.3)$ & $5.3(1.7)$ & $6.7(1.4)$ & $6.5(1.4)$ & $7.0(1.8)$ & $6.2(1.1)$ \\
\hline \multicolumn{7}{|l|}{ Location, n (\%) } \\
\hline At level of SCl & I (5.6) & $2(16.7)$ & - & $25(23.7)$ & - & $7(20.6)$ \\
\hline Below level of $\mathrm{SCl}$ & $6(33.3)$ & $5(4 I .7)$ & - & $53(50.0)$ & - & $14(4 \mid .2)$ \\
\hline Both & II (6I.I) & $5(41.7)$ & - & $28(26.3)$ & - & $13(38.2)$ \\
\hline
\end{tabular}

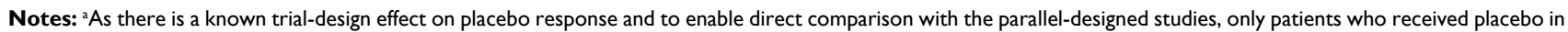
the first arm were included for the analysis. ${ }^{b}$ American Spinal Injury Association (ASIA) Impairment Scale: A, no sensory or motor function is preserved; B, sensory function is preserved below the level of the injury, but there is no motor function; $\mathrm{C}$, sensory and motor functions are preserved below the neurologic level, and more than half of the key muscles below the neurologic level have a muscle grade of $<3$; D, sensory and motor functions are preserved below the neurologic level, and at least half of the key muscles below the neurologic level have a muscle grade of $>3$. 'Baseline pain levels were assessed using a I I-point Numeric Rating Scale ( $0=$ no pain, I0=worst possible pain). Abbreviation: $\mathrm{SCl}$, spinal cord injury.

placebo responses. Overall, placebo responses among individuals with neuropathic pain due to SCI were small and difficult to predict at the subject level.

\section{Low placebo response hallmarks SCl clinical trials}

According to our meta-analysis, individuals with SCI and neuropathic pain have no significant placebo response in clinical trials testing pharmacologic interventions lasting 4 weeks or longer. This finding is in agreement with the small effect we previously reported, ${ }^{12}$ but is in stark contrast to the majority of other chronic pain conditions. ${ }^{40-46}$ Emerging clinical trial data have further substantiated our observation of limited placebo response in SCI patients. In a recent trial demonstrating the efficacy of botulinum toxin type A (BTXA), fewer than $10 \%$ of SCI patients administered saline achieved a meaningful reduction in pain (i.e., $>30 \%) .{ }^{47}$ Comparatively, approximately almost half of the patients with myofascial pain in a similarly designed BTXA clinical trial (i.e., also 4 weeks in duration, parallel design) responded (i.e., $>30 \%$ reduction in pain) to the administration of saline.$^{48}$ In a BTXA clinical trial, large placebo responses are expected, given the invasiveness of the intervention compared with conventional pharmacologic studies. ${ }^{49,50}$ 
Placebo response
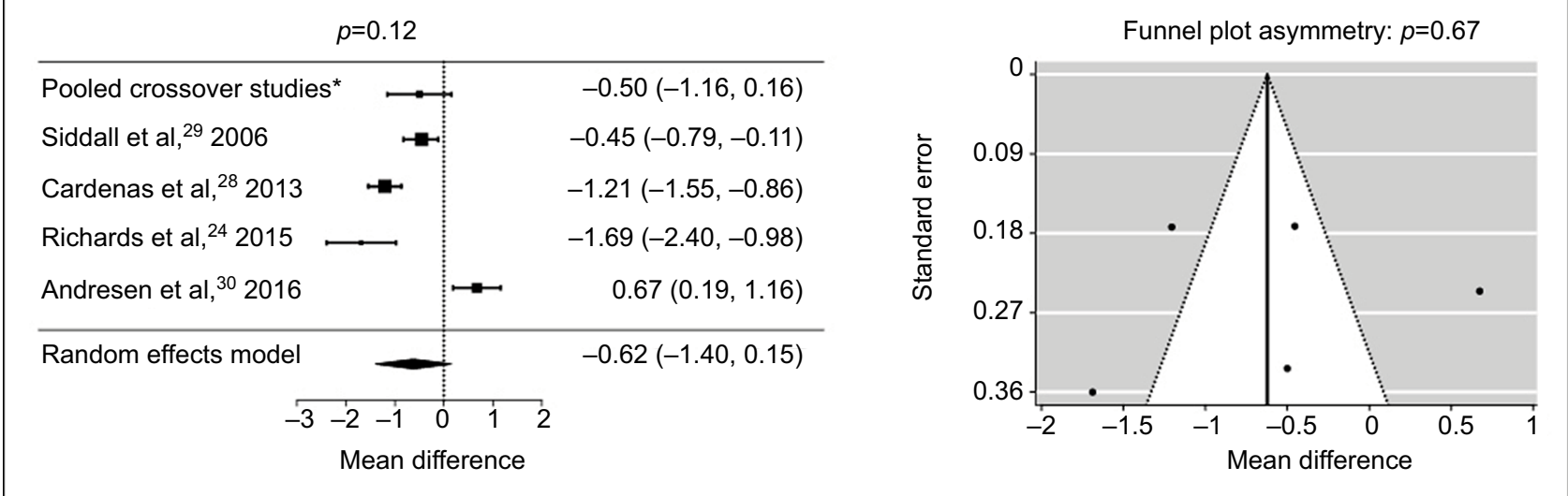

Figure 2 Change in pain intensity in the placebo group for all studies.

Notes: A negative mean difference indicates a reduction in pain score after placebo treatment. Funnel plot: standard error against mean change in pain intensity for the placebo group for all studies. *Finnerup 2002 and Finnerup 2009:22,23 cross-over designed studies. As there is a known trial-design effect on placebo response and to enable direct comparison with the parallel-designed studies, only patients who received placebo in the first arm were included for the analysis. To increase the sample size these two studies were pooled.

While there was no overall significant placebo response, three trials demonstrated average reductions in pain intensity ratings with placebo. The largest placebo response was reported in a recent trial conducted in the USA. ${ }^{24}$ Comparatively, the most recent trial conducted in Europe reported no discernible placebo response..$^{30}$ Collectively, these observations correspond with findings that indicate that placebo responses are increasing in American neuropathic pain clinical trials. ${ }^{51}$ However, the high placebo response in the American trial ${ }^{24}$ should be interpreted with caution as the study was focused on depression, which may confound the results; the placebo response rate in depression consistently falls between $20 \%$ and $40 \%$ (e.g., improvement on the 29-item modified Hamilton Depression Scale). ${ }^{52-55}$

The presence of damage in the CNS represents the most distinguishing physiologic/anatomical feature that could explain small placebo responses in individuals with SCI. In principle, damage in the spinal cord disrupts normal physiology involved in generating placebo analgesia, thereby reducing the capacity to experience placebo response. ${ }^{56-58}$ Our subject-level meta-analysis indicates a trend to this effect, namely, that individuals with more complete injuries tended to exhibit smaller placebo responses than individuals with incomplete injuries (Figure 7). Comparatively, level of injury (i.e., para versus tetra) had no discernible impact on placebo responses. The impact of injury severity on individual placebo responses was not, however, consistent enough across trials to yield an overall effect. A variable effect of injury severity on placebo responses may be related to a number of factors, including that a clinical measure of damage in the spinal cord (i.e., AIS grades) is insufficient to characterize the extent of pathology in spinal pathways involved in placebo analgesia. From a pragmatic perspective, injury completeness may only have a subtle effect, while other factors play a much larger role in placebo (e.g., expectation). ${ }^{5,59-62}$

\section{Predictors of placebo response}

Reductions in pain were predicted by baseline ratings, insofar as patients with higher ratings demonstrated larger placebo responses. This is consistent with the notion that enrollment in clinical trials occurs when pain intensity is at its peak, and that a follow-up measurement is biased to decrease (i.e., regression toward the mean) ${ }^{63}$ Our observations also indicate that male patients have larger placebo responses than females. With regard to sex-related differences, other studies have reported similar observations ${ }^{64-66}$ or no effect of sex ${ }^{67}$ Caution interpreting the effect of sex is warranted on the basis that the vast majority of subjects examined herein were male, consistent with the typical demographics of SCI ${ }^{68}$

If not related to damage in the spinal cord, what factors unique to SCI explain markedly low placebo responses (i.e., no significant response across all trials)? SCI neuropathic pain is commonly regarded as a chronic condition refractory to treatment. ${ }^{69,70}$ This, in turn, could decrease expectation of benefit and drive lower placebo responses. ${ }^{71}$ The unique complexities of neuropathic pain, including that pain symptoms arise from other secondary health complications (e.g., infections, spasticity, and pressure ulcers to name a few), may also contribute to low placebo responses. Finally, all of the IPD included in our meta-analysis are all from preapproval trials 


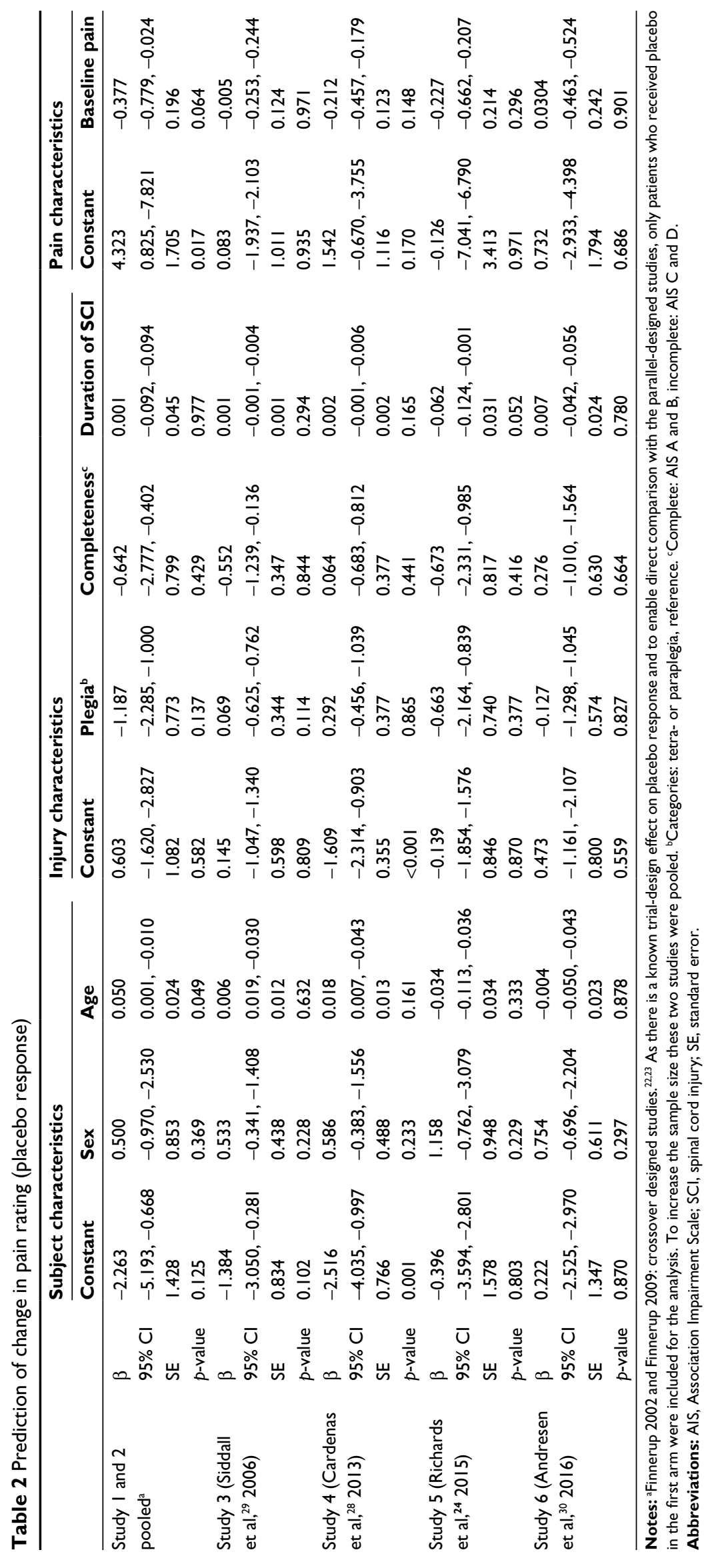




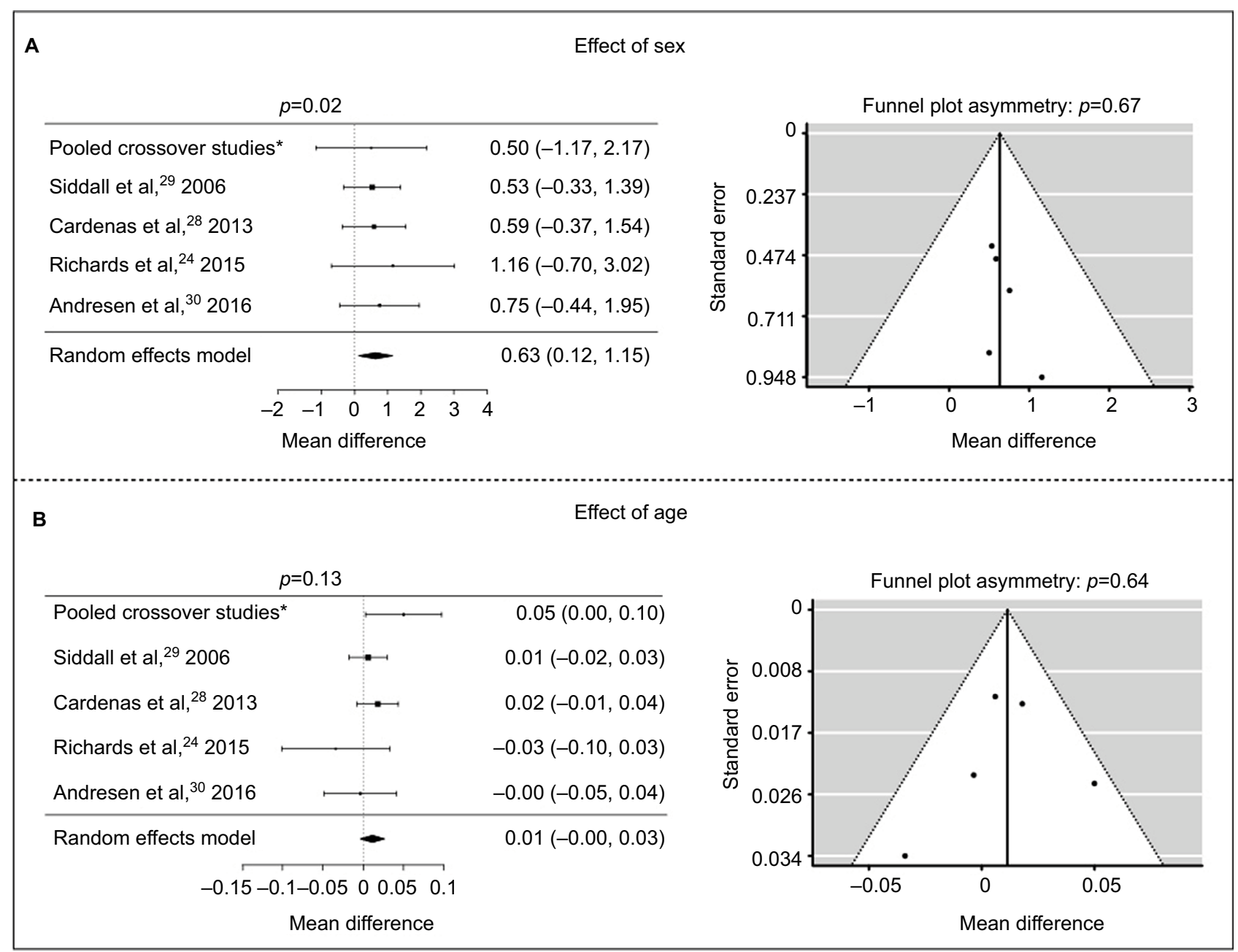

Figure 3 Effect of patients' characteristics on the placebo response.

Notes: (A) Age had no modulatory effect on the placebo response. (B) There was a significant main effect of sex. That is, being male was associated with higher placebo response. A negative mean difference indicates a reduction in pain score after placebo treatment. *Finnerup 2002 and Finnerup $2009: 22,23$ cross-over designed studies. As there is a known trial-design effect on placebo response and to enable direct comparison with the parallel-designed studies, only patients who received placebo in the first arm were included for the analysis. To increase the sample size these two studies were pooled.

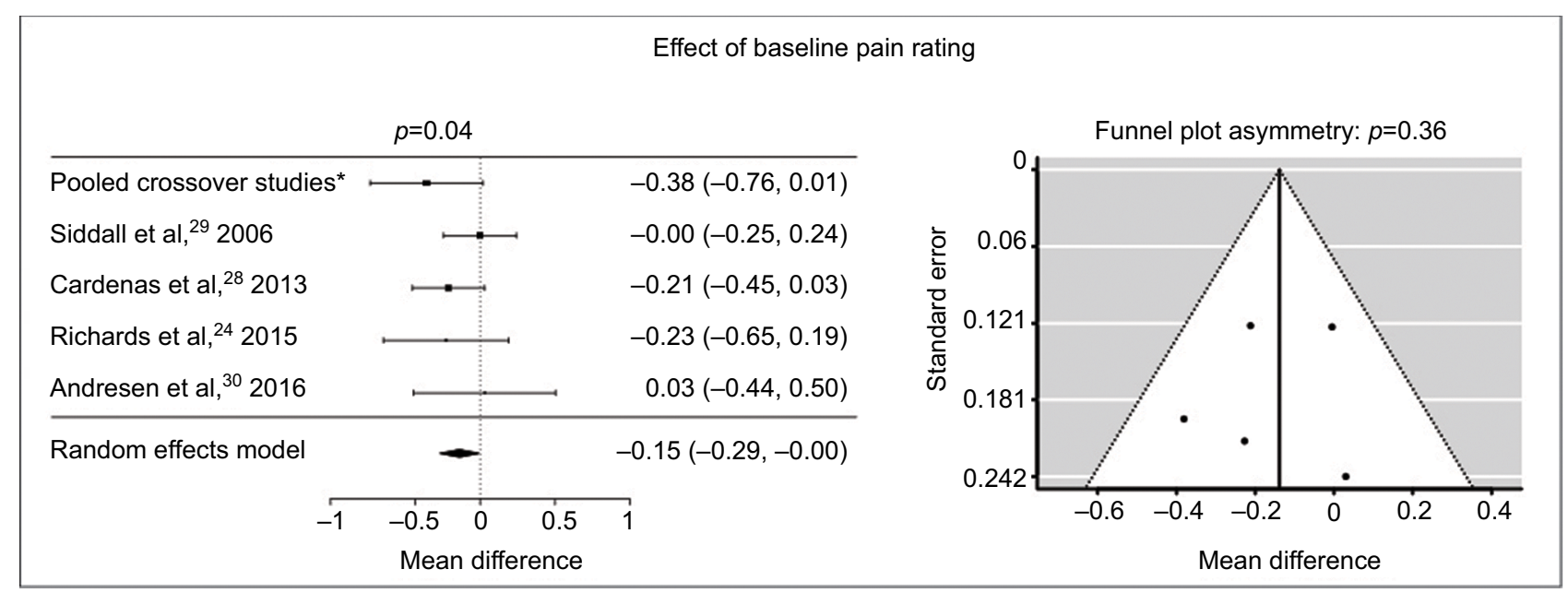

Figure 4 Effect of baseline pain intensity and duration of placebo treatment.

Notes: Higher baseline pain ratings at baseline were associated with greater placebo responses. A negative mean difference indicates a reduction in pain score after placebo treatment. *Finnerup 2002 and Finnerup 2009: cross-over designed studies. ${ }^{22,23}$ As there is a known trial-design effect on placebo response and to enable direct comparison with the parallel-designed studies, only patients who received placebo in the first arm were included for the analysis. To increase the sample size these two studies were pooled. 


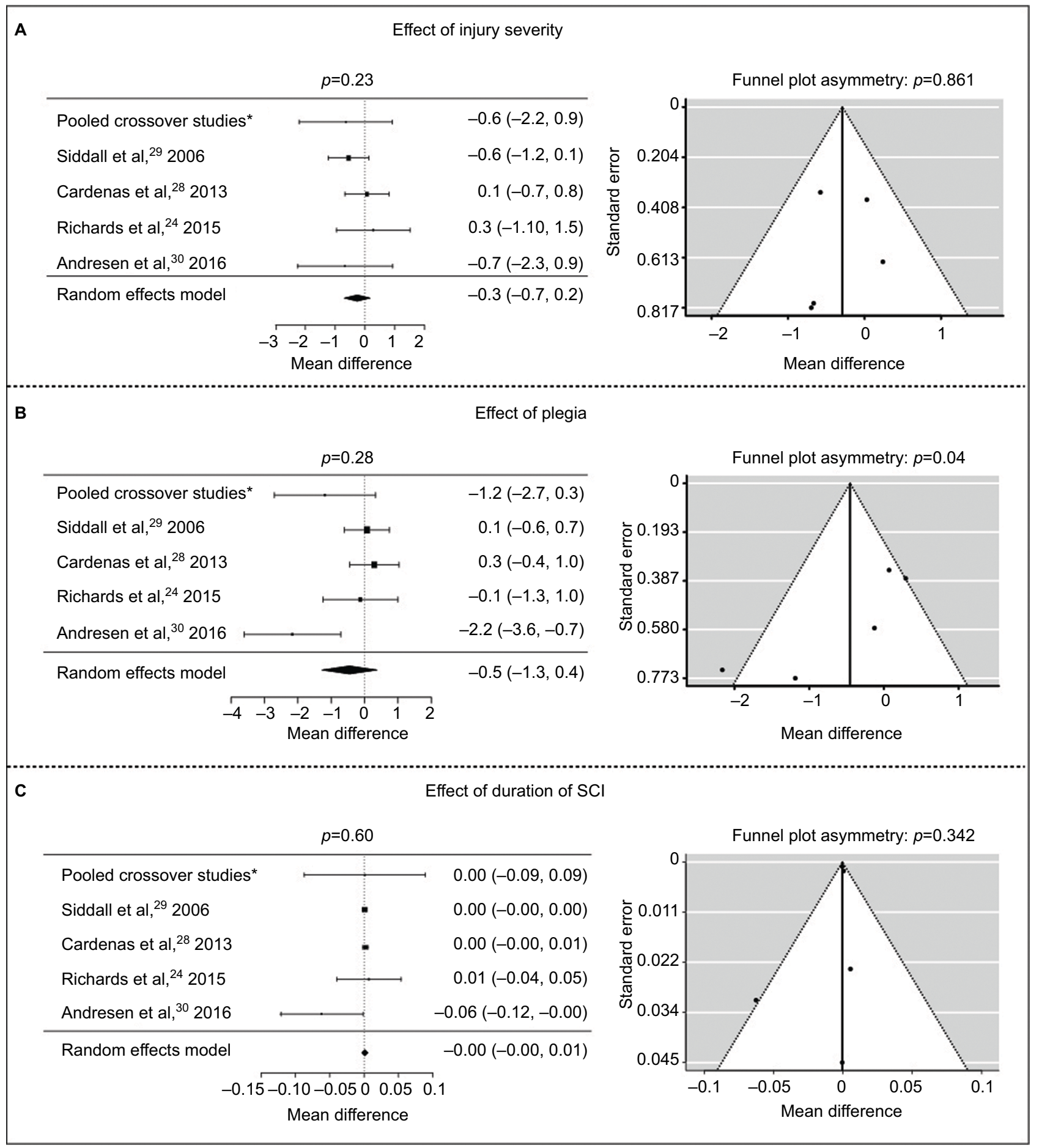

Figure 5 Effect of injury characteristics on the placebo response.

Notes: The placebo response was not affected by $(\mathbf{A})$ injury completeness, (B) type of plegia (i.e., para- or tetraplegia), and (C) duration of spinal cord injury (SCl). A negative mean difference indicates a reduction in pain score after placebo treatment. *Finnerup 2002 and Finnerup 2009:22,23 Cross-over designed studies. As there is a known trialdesign effect on placebo response and to enable direct comparison with the parallel-designed studies, only patients who received placebo in the first arm were included for the analysis. To increase the sample size these two studies were pooled.

Abbreviation: $\mathrm{SCl}$, spinal cord injury.

(i.e., none were performed after a drug had been approved for use in SCI neuropathic pain). Larger responses are associated with postapproval trials. ${ }^{72}$ Future studies trialing pregabalin (i.e., a drug now approved for use in SCI neuropathic pain) could expect larger placebo responses than reported here.

\section{Limitations of the study}

There are some limitations of our analysis. The low number of trials limits the results of our IPD meta-analysis. Despite many advantages compared to conventional group-level meta-analyses, ${ }^{15}$ individual patient-level meta-analysis will remain limited 


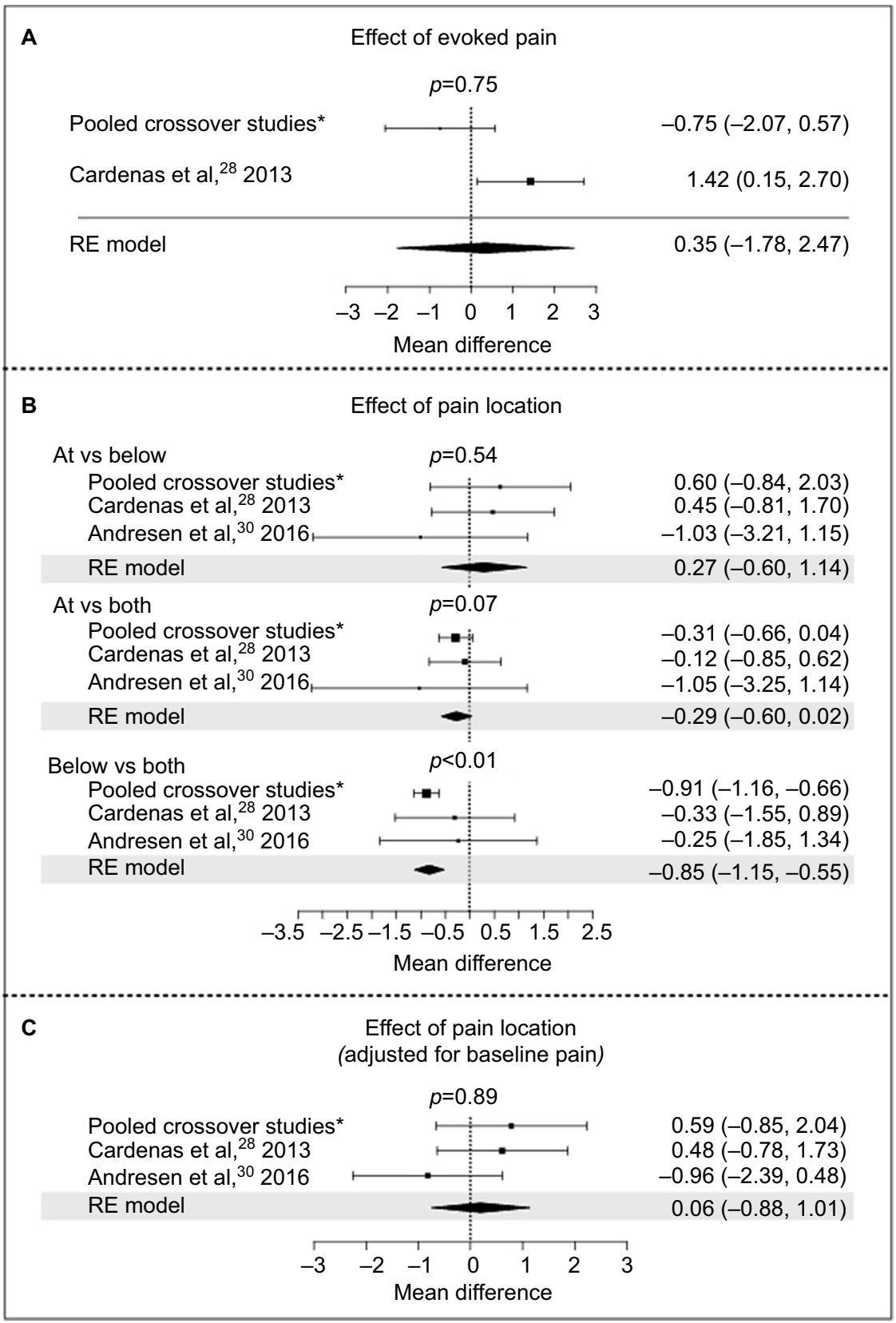

Figure 6 Effect evoked pain and pain location of pain (i.e., at level, below level, or both) on the placebo response.

Notes: A negative mean difference indicates a reduction in pain score after placebo treatment. (A) The presence of evoked pain had no modulatory effect on the placebo response. (B) No difference in placebo response was detected between patients with at-level pain and patients with below level pain or both. Patients with below pain exhibited higher placebo responses compared to those who had at- and below level pain (i.e., both). (C) However, this effect of location was diminished when adjusting for baseline pain rating. Thus, the effect was only related to the baseline pain being higher. *Finnerup 2002 and Finnerup 2009:22,23 Cross-over designed studies. As there is a known trial-design effect on placebo response and to enable direct comparison with the parallel-designed studies, only patients who received placebo in the first arm were included for the analysis. To increase the sample size these two studies were pooled.

Abbreviation: RE, random effects.

by the inclusion of "accessible" study data. While accessibility is undoubtedly improving, open access data repositories with sufficient information to perform secondary data analyses are urgently needed. ${ }^{73}$ In addition to accessing data, important variables, such as a measure of expectation (e.g., whether a patient accurately predicted if they were in the placebo group), were not examined. As a surrogate of expectation, we did consider duration of injury. That duration had no effect on placebo responses may reflect that only chronic subjects were included ( $>4.6$ years postinjury on average, see Table 1). Future studies should aim to systematically address expectation in both the placebo and active treatment groups. ${ }^{59-62,74-76}$ 


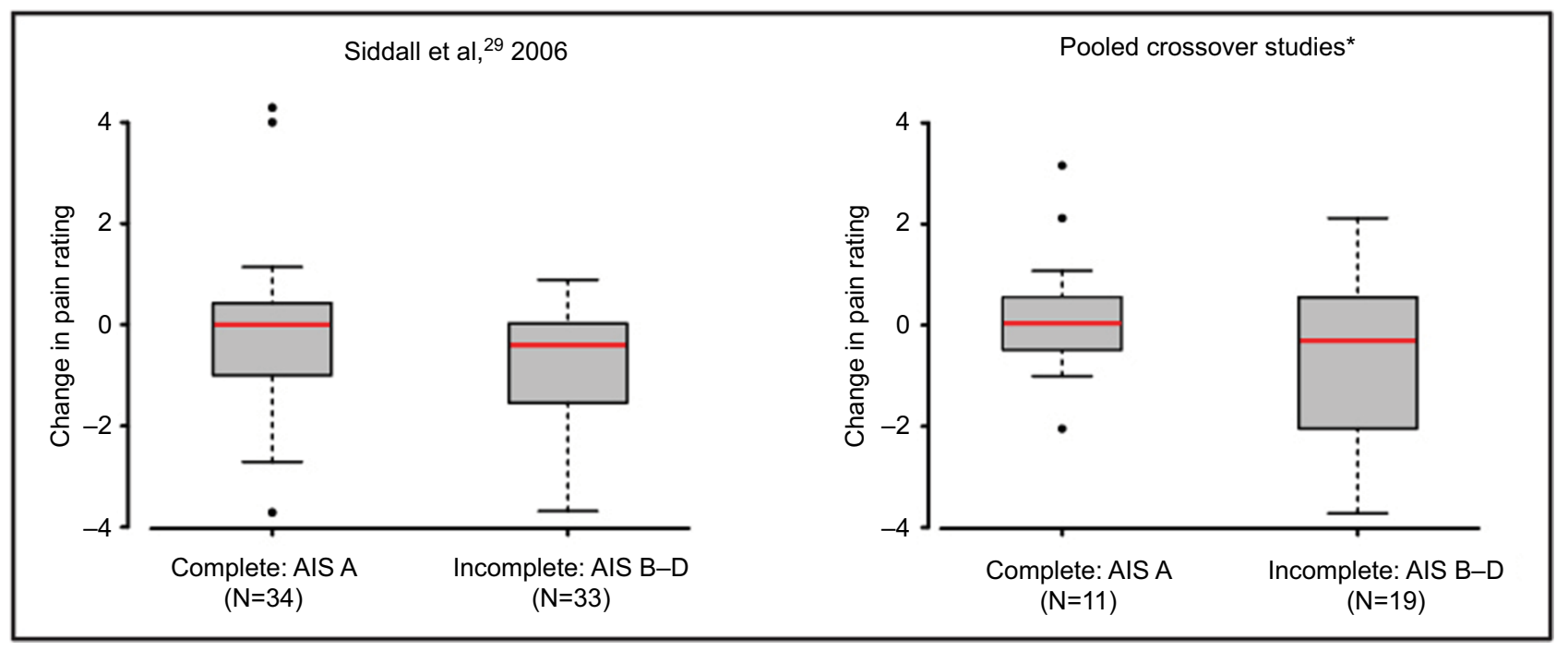

Figure 7 Effect of injury completeness on placebo response.

Notes: There was a trend towards larger placebo responses in individuals with incomplete injuries (versus complete). A negative change in pain rating indicates a reduction in pain score after placebo treatment. *Finnerup 2002 and Finnerup 2009:22,23 Cross-over designed studies. As there is a known trial-design effect on placebo response and to enable direct comparison with the parallel-designed studies, only patients who received placebo in the first arm were included for the analysis. To increase the sample size these two studies were pooled

Abbreviation: AIS, Association Impairment Scale.

\section{Conclusion}

Our meta-analysis of IPD demonstrates that low placebo responses are a hallmark of neuropathic pain in RCTs of individuals with chronic SCI. Contrasting the hypothesis that disease-specific factors contribute to lower placebo responses, injury and pain characteristics were not predictive of changes in pain rating. All identified predictors - baseline pain and sex - are not disease-specific and, thus, poorly explain a reduced capacity to report placebo. These factors, however, still remain crucial to consider when designing clinical trials.

\section{Acknowledgments}

Data for this research were provided by Pfizer's Clinical Trial Data Request Program (Study ID\# WI205957). Pfizer had no role in the study design, data collection, statistical analysis, interpretation, or writing of the manuscript. The corresponding author was responsible for the content of the manuscript and the decision to submit for publication. CRJ is supported by postdoctoral research fellowships of the International Foundation for Research in Paraplegia (IRP), the Swiss National Science Foundation, and Craig H. Neilsen Foundation. FMW is supported by a University of British Columbia 4-Year Research Fellowship. CM is supported by a salary award from Fonds de recherché Québec - Santé (FRQS). JJC is supported by the Branco Weiss Fellowship - Society in Science and by the Michael Smith Foundation for Health Research (MSFHR). JLKK is a MSFHR and Rick Hansen Institute Scholar, and is also supported by Wings For Life, IRP, and the Canadian Institutes of Health Research.

\section{Disclosure}

The authors report no conflicts of interest in this work.

\section{References}

1. Katz J, Finnerup NB, Dworkin RH. Clinical trial outcome in neuropathic pain: relationship to study characteristics. Neurology. 2008;70(4):263-272.

2. Martini AC, Berta T, Forner S, et al. Lipoxin A4 inhibits microglial activation and reduces neuroinflammation and neuropathic pain after spinal cord hemisection. J Neuroinflammation. 2016;13(1):75.

3. Forner S, Martini AC, de Andrade EL, Rae GA. Neuropathic pain induced by spinal cord injury: role of endothelin ETA and ETB receptors. Neurosci Lett. 2016;617:14-21.

4. Berge OG. Predictive validity of behavioural animal models for chronic pain. Br J Pharmacol. 2011;164(4):1195-1206.

5. Vase L, Vollert J, Finnerup NB, et al. Predictors of the placebo analgesia response in randomized controlled trials of chronic pain: a meta-analysis of the individual data from nine industrially sponsored trials. Pain. 2015;156(9):1795-1802.

6. Simmonds MC, Higgins JP, Stewart LA, Tierney JF, Clarke MJ, Thompson SG. Meta-analysis of individual patient data from randomized trials: a review of methods used in practice. Clin Trials. 2005;2(3):209-217.

7. FuY, Persson MS, Bhattacharya A, et al. Identifying placebo responders and predictors of response in osteoarthritis: a protocol for individual patient data meta-analysis. Syst Rev. 2016;5(1):183.

8. Osterberg A, Boivie J, Thuomas KA. Central pain in multiple sclerosisprevalence and clinical characteristics. Eur J Pain. 2005;9(5):531-542.

9. Paolucci S, Iosa M, Toni D, et al; Neuropathic pain special interest group of the Italian Neurological Society. Prevalence and time course of post-stroke pain: a multicenter prospective hospital-based study. Pain Med. 2016;17(5):924-930. 
10. Burke D, Fullen BM, Stokes D, Lennon O. Neuropathic pain prevalence following spinal cord injury: a systematic review and meta-analysis. Eur J Pain. 2016;21(1):29-44.

11. Cepeda MS, Berlin JA, Gao CY, Wiegand F, Wada DR. Placebo response changes depending on the neuropathic pain syndrome: results of a systematic review and meta-analysis. Pain Med. 2012;13(4):575-595.

12. Cragg JJ, Warner FM, Finnerup NB, et al. Meta-analysis of placebo responses in central neuropathic pain: impact of subject, study, and pain characteristics. Pain. 2015;157(3):530-540.

13. Burns PB, Rohrich RJ, Chong KC. The levels of evidence and their role in evidence-based medicine. Plast Reconstr Surg. 2011;128(1):305-310.

14. Barton S. Which clinical studies provide the best evidence? BMJ. 2000;321(7256):255-256.

15. Stewart LA, Parmar MK. Meta-analysis of the literature or of individual patient data: is there a difference? Lancet. 1993;341(8842):418-422.

16. Stewart LA, Tierney JF. To IPD or not to IPD? Eval Health Prof. 2002; 25(1):76-97.

17. Stewart LA, Clarke MJ. Practical methodology of meta-analyses (overviews) using updated individual patient data. Stat Med. 1995;14(19) 2057-2079.

18. Riley RD, Lambert PC, Abo-Zaid G. Meta-analysis of individual participant data: rationale, conduct, and reporting. BMJ. 2010;340:c221

19. Debray TP, Moons KG, van Valkenhoef G, et al; Get Real Methods Review Group. Get real in individual participant data (IPD) meta-analysis: a review of the methodology. Res Synth Methods. 2015;6(4):293-309.

20. Simmonds M, Stewart G, Stewart L. A decade of individual participant data meta-analyses: a review of current practice. Contemp Clin Trials. 2015;45(Pt A):76-83.

21. Kirshblum SC, Burns SP, Biering-Sorensen F, et al. International standards for neurological classification of spinal cord injury (Revised 2011). J Spinal Cord Med. 2011;34(6):535-546.

22. Finnerup NB, Grydehøj J, Bing J, et al. Levetiracetam in spinal cord injury pain: a randomized controlled trial. Spinal Cord. 2009;47(12): 861-867.

23. Finnerup NB, Sindrup SH, Bach FW, Johannesen IL, Jensen TS Lamotrigine in spinal cord injury pain: a randomized controlled trial. Pain. 2002;96(3):375-383.

24. Richards JS, Bombardier CH, Wilson CS, et al. Efficacy of venlafaxine XR for the treatment of pain in patients with spinal cord injury and major depression: a randomized, controlled trial. Arch Phys Med Rehabil. 2015;96(4):680-689.

25. Cardenas DD, Warms CA, Turner JA, Marshall H, Brooke MM, Loeser JD. Efficacy of amitriptyline for relief of pain in spinal cord injury: results of a randomized controlled trial. Pain. 2002;96(3):365-373.

26. Viechtbauer $\mathrm{W}$. Conducting meta-analyses in $\mathrm{R}$ with the metafor package. J Stat Softw. 2010;36(3):1-48.

27. Egger M, Davey Smith G, Schneider M, Minder C. Bias in meta-analysis detected by a simple, graphical test. Br Med J. 1997;315(7109):629-634.

28. Cardenas DD, Nieshoff EC, Suda K, et al. A randomized trial of pregabalin in patients with neuropathic pain due to spinal cord injury. Neurology. 2013;80(6):533-539.

29. Siddall PJ, Cousins MJ, Otte A, Griesing T, Chambers R, Murphy TK. Pregabalin in central neuropathic pain associated with spinal cord injury: a placebo-controlled trial. Neurology. 2006;67(10):1792-1800.

30. Andresen SR, Bing J, Hansen RM, et al. Ultramicronized palmitoylethanolamide in spinal cord injury neuropathic pain: a randomized, double-blind, placebo-controlled trial. Pain. 2016;157(9):2097-2103.

31. Rintala DH, Holmes SA, Courtade D, Fiess RN, Tastard LV, Loubser PG. Comparison of the effectiveness of amitriptyline and gabapentin on chronic neuropathic pain in persons with spinal cord injury. Arch Phys Med Rehabil. 2007;88(12):1547-1560.

32. Finnerup NB, Biering-Sørensen F, Johannesen IL, et al. Intravenous lidocaine relieves spinal cord injury pain: a randomized controlled trial. Anesthesiology. 2005;102(5):1023-1030.

33. Kvarnstrom A, Karlsten R, Quiding H, Gordh T. The analgesic effect of intravenous ketamine and lidocaine on pain after spinal cord injury. Acta Anaesthesiol Scand. 2004;48(4):498-506.
34. Tai Q, Kirshblum S, Chen B, Millis S, Johnston M, DeLisa JA. Gabapentin in the treatment of neuropathic pain after spinal cord injury: a prospective, randomized, double-blind, crossover trial. J Spinal Cord Med. 2002;25(2):100-105.

35. Levendoglu F, Ogun CO, Ozerbil O, Ogun TC, Ugurlu H. Gabapentin is a first line drug for the treatment of neuropathic pain in spinal cord injury. Spine (Phila Pa 1976). 2004;29(7):743-751.

36. Eide PK, Stubhaug A, Stenehjem AE. Central dysesthesia pain after traumatic spinal cord injury is dependent on N-methyl-D-aspartate receptor activation. Neurosurgery. 1995;37(6):1080-1087.

37. Chiou-Tan FY, Tuel SM, Johnson JC, Priebe MM, Hirsh DD, Strayer JR. Effect of mexiletine on spinal cord injury dysesthetic pain. Am J Phys Med Rehabil. 1996;75(2):84-87.

38. Amr YM. Multi-day low dose ketamine infusion as adjuvant to oral gabapentin in spinal cord injury related chronic pain: a prospective, randomized, double blind trial. Pain Physician. 2010;13(3):245-249.

39. Davidoff G, Guarracini M, Roth E, Sliwa J, Yarkony G. Trazodone hydrochloride in the treatment of dysesthetic pain in traumatic myelopathy: a randomized, double-blind, placebo-controlled study. Pain. 1987;29(2):151-161.

40. Carvalho C, Caetano JM, Cunha L, Rebouta P, Kaptchuk TJ, Kirsch I. Open-label placebo treatment in chronic low back pain: a randomized controlled trial. Pain. 2016;157(12):2766-2772.

41. Yunus MB, Masi AT, Aldag JC. Short term effects of ibuprofen in primary fibromyalgia syndrome: a double blind, placebo controlled trial. J Rheumatol. 1989;16(4):527-532.

42. Staud R, Weyl E, Bartley E, Price D, Robinson M. Muscle injections produce clinically significant analgesic effects in patients with fibromyalgia syndrome. J Pain. 2013;14(4):S65.

43. Harden RN, Gracely RH, Carter T, Warner G. The placebo effect in acute headache management: ketoralac, meperidine, and saline in the emergency department. 1995;36(6):352-356.

44. Puhl AA, Reinhart CJ, Rok ER, Injeyan HS. An examination of the observed placebo effect associated with the treatment of low back pain - a systematic review. Pain Res Manag. 2011;16(1):45-52.

45. Prior MJ, Codispoti JR, Fu M. A randomized, placebo-controlled trial of acetaminophen for treatment of migraine headache. Headache. 2010;50(5):819-833.

46. Lam PH, Hansen K, Keighley G, Hackett L, Murrell GA. A randomized, double-blinded, placebo-controlled clinical trial evaluating the effectiveness of daily vibration after arthroscopic rotator cuff repair. Am J Sport Med. 2015;43(11):2774-2782.

47. Han ZA, Song DH, Oh HM, Chung ME. Botulinum toxin type A for neuropathic pain in patients with spinal cord injury. Ann Neurol. 2016;79(4):569-578.

48. Qerama E, Fuglsang-Frederiksen A, Kasch H, Bach FW, Jensen TS. A double-blind, controlled study of botulinum toxin A in chronic myofascial pain. Neurology. 2006;67(2):241-245.

49. Zhang W, Robertson J, Jones AC, Dieppe PA, Doherty M. The placebo effect and its determinants in osteoarthritis: meta-analysis of randomised controlled trials. Ann Rheum Dis. 2008;67(12):1716-1723.

50. Lang EV, Hatsiopoulou O, Koch T, et al. Can words hurt? Patient-provider interactions during invasive procedures. Pain. 2005;114(1-2):303-309.

51. Tuttle AH, Tohyama S, Ramsay $\mathrm{T}$, et al. Increasing placebo responses over time in U.S. clinical trials of neuropathic pain. Pain. 2015;156(12): 2616-2626.

52. Nava RA. Clinical pharmacology. Ulster Med J. 1966;49(2):116.

53. Brown WA. Placebo as a treatment for depression. Neuropsychopharmacology. 1994;10(4):265-269.

54. McGrath PJ, Stewart JW, Quitkin FM, et al. Gepirone treatment of atypical depression: preliminary evidence of serotonergic involvement. J Clin Psychopharmacol. 1994;14(5):347-352.

55. Davidson JR, Abraham K, Connor KM, McLeod MN. Effectiveness of chromium in atypical depression: a placebo-controlled trial. Biol Psychiatry. 2003;53(3):261-264.

56. Eippert F, Finsterbusch J, Bingel U, Büchel C. Direct evidence for spinal cord involvement in placebo analgesia. Science. 2009;326(5951):404. 
57. Matre D, Casey KL, Knardahl S. Placebo-induced changes in spinal cord pain processing. J Neurosci. 2006;26(2):559-563.

58. Benedetti F, Mayberg H, Wager T, Stohler C, Zubieta JK. Neurobiological mechanisms of the placebo effect. J Neurosci. 2005;25(45):10390-10402.

59. Bingel U, Wanigasekera V, Wiech $\mathrm{K}$, et al. The effect of treatment expectation on drug efficacy: imaging the analgesic benefit of the opioid remifentanil. Sci Transl Med. 2011;3(70):70ra14.

60. Kirsch I. How Expectancies Shape Experience. Washington, DC, US: American Psychological Association. 1999.

61. Price DD, Milling LS, Kirsch I, Duff A, Montgomery GH, Nicholls SS. An analysis of factors that contribute to the magnitude of placebo analgesia in an experimental paradigm. Pain. 1999;83(2):147-156.

62. Vase L, Robinson ME, Verne GN, Price DD. The contributions of suggestion, desire, and expectation to placebo effects in irritable bowel syndrome patients: an empirical investigation. Pain. 2003;105(1-2):17-25.

63. Turner JA, Deyo RA, Loeser JD, Von Korff M, Fordyce WE. The importance of placebo effects in pain treatment and research. JAMA. 1994;271(20):1609-1614.

64. Aslaksen PM, Flaten MA. The roles of physiological and subjective stress in the effectiveness of a placebo on experimentally induced pain. Psychosom Med. 2008;70(7):811-818.

65. Flaten MA, Aslaksen PM, Finset A, Simonsen T, Johansen O. Cognitive and emotional factors in placebo analgesia. J Psychosom Res. 2006;61(1): $81-89$.

66. Berman S, Munakata J, Naliboff BD, et al. Gender differences in regional brain response to visceral pressure in IBS patients. Eur J Pain. 2000;4(2):157-172.
67. Averbuch M, Katzper M. Gender and the placebo analgesic effect in acute pain. Clin Pharmacol Ther. 2001;70(3):287-291.

68. Singh A, Tetreault L, Kalsi-Ryan S, Nouri A, Fehlings MG. Global prevalence and incidence of traumatic spinal cord injury. Clin Epidemiol. 2014;6:309-331.

69. Frisbie JH, Aguilera EJ. Chronic pain after spinal cord injury: an expedient diagnostic approach. Paraplegia. 1990;28(7):460-465.

70. Dalyan M, Cardenas D, Gerard B. Upper extremity pain after spinal cord injury. Spinal Cord. 1999;37(3):191-195.

71. Colloca L, Klinger R, Flor H, Bingel U. Placebo analgesia: psychological and neurobiological mechanisms. Pain. 2013;154(4):511-514.

72. Freeman R, Emir B, Parsons B. Predictors of placebo response in peripheral neuropathic pain: insights from pregabalin clinical trials. J Pain Res. 2015;8:257-268.

73. Kramer JLK, Geisler F, Ramer L, Plunet W, Cragg JJ. Open access platforms in spinal cord injury: existing clinical trial data to predict and improve outcomes. Neurorehabil Neural Repair. 2017;31(5): 399-401.

74. Wager TD, Rilling JK, Smith EE, et al. Placebo-induced changes in FMRI in the anticipation and experience of pain. Science. 2004;303(5661): $1162-1167$.

75. Petrovic P, Kalso E, Petersson KM, Ingvar M. Placebo and opioid analgesia-imaging a shared neuronal network. Science. 2002;295(5560): $1737-1740$.

76. Kong J. Brain activity associated with expectancy-enhanced placebo analgesia as measured by functional magnetic resonance imaging. J Neurosci. 2006;26(2):381-388.
Journal of Pain Research

\section{Publish your work in this journal}

The Journal of Pain Research is an international, peer reviewed, open access, online journal that welcomes laboratory and clinical findings in the fields of pain research and the prevention and management of pain. Original research, reviews, symposium reports, hypothesis formation and commentaries are all considered for publication.

\section{Dovepress}

The manuscript management system is completely online and includes a very quick and fair peer-review system, which is all easy to use. Visit http://www.dovepress.com/testimonials.php to read real quotes from published authors. 